\title{
Yersinia massiliensis sp. nov., isolated from fresh water
}

Correspondence Michel Drancourt Michel.Drancourt@ medecine.univ-mrs.fr

\author{
Vicky Merhej, Toïdi Adékambi, Isabelle Pagnier, Didier Raoult \\ and Michel Drancourt
}

AP-HM Timone, Fédération de Microbiologie Clinique and Unité des Rickettsies CNRS UMR 6020, IFR 48, Faculté de Médecine, Université de la Méditerranée, Marseille, France

Two bacterial organisms, $50640^{\top}$ and 823 , were isolated from fresh water in Marseilles, France, and were further identified as members of the genus Yersinia on the basis of their phenotypic characteristics and 16S rRNA gene sequencing. Their unique phenotypic profile differed from that of closely related species of Yersinia bercovieri and Yersinia mollaretii by exhibiting positive indole and inositol tests, and from that of Yersinia frederiksenii by lacking the ability to ferment L-rhamnose. A polyphasic approach, including almost complete 16S rRNA gene sequencing (1461 bp) and partial sequencing of $h s p 60$ (683 bp), gyrB (662 bp), sodA (624 bp) and rpoB (1049 bp) showed that isolates $50640^{\top}$ and 823 exhibited 98.5, 93.5, 90.4, 92.4 and $96.6 \%$ similarity with $Y$. mollaretii, 98.7, 93.0, 90.1, 89.1 and 96.2\% with $Y$. bercovieri, and 98.4, 93.2, 89.8, 88.9 and $95.2 \%$ with $Y$. frederiksenii, respectively. Both isolates exhibited an identical $16 \mathrm{~S}$ rRNA gene sequence and differed by one to five point mutations in housekeeping gene sequences. Phylogenetic reconstructions based on the combination of these four housekeeping genes indicated that the two isolates formed a unique branch supported by a bootstrap value of $93 \%$. Their unique phenotypic traits, 16S rRNA gene sequence, together with housekeeping gene sequences exhibiting $<97 \%$ similarity with closely related species, and phylogenetic analyses suggested that the two isolates represent a so far undescribed Yersinia species. The name Yersinia massiliensis sp. nov. is proposed for this new taxon (type strain $50640^{\top}=\mathrm{CIP}$ $109351^{\top}=$ CCUG $53443^{\top}$; isolate $823=$ CIP $109352=$ CCUG 53444).
At the time of writing, the genus Yersinia consists of 12 species, including Yersinia pestis (the plague agent), Yersinia enterocolitica and Yersinia pseudotuberculosis (the two species responsible for a complex clinical condition known as yersiniosis) (Perry \& Fetherston, 1997; Bottone, 1999; Carniel \& Mollaret, 1990), and nine Y. enterocolitica-like species, i.e. Yersinia frederiksenii, Yersinia intermedia, Yersinia kristensenii, Yersinia bercovieri, Yersinia mollaretii, Yersinia rohdei, Yersinia ruckeri, Yersinia aldovae (Sulakvelidze, 2000) and Yersinia aleksiciae (Sprague \& Neubauer, 2005). Except for $Y$. pestis, Yersinia species are ubiquitous and have been found in soil, fresh water sources, animals, foods and sewage (Bercovier \& Mollaret, 1984; Bottone, 1997; Sulakvelidze, 2000). They have been occasionally isolated from clinical specimens (Gray, 1995) and virulence factors have been

The GenBank/EMBL/DDBJ accession numbers for the gene sequences of isolates $50640^{\top}$ and 823 are EF179119 and EF179120 (16S rRNA gene), EF173172 and EF173177 (hsp60), EF175588 and EF175591 (gyrB), EF175618 and EF175621 (sodA), and EF175599 and EF175600 (rpoB), respectively.

Phylogenetic trees based on $r p o B, h s p 60$, gyrB and sod $A$ gene sequences of isolates $50640^{\top}$ and 823 and 11 Yersinia species are available with the online version of this paper. detected in several isolates of these species (Robins-Browne et al., 1991; Sulakvelidze et al., 1999; Sulakvelidze, 2000). Herein we have characterized two freshwater Yersinia isolates by extensive phenotypic and molecular methods and found them to exhibit unique characteristics, suggesting that they are representative of a hitherto undescribed Yersinia species.

Isolate $50640^{\mathrm{T}}$ was isolated in a dialysis unit from the hospital water distribution system in Marseilles, France, and isolate 823 came from a well in another part of southern France. Water specimens were filtered through a $0.45 \mu \mathrm{m}$ nitrocellulose filter membrane (Millipore) and incubated at $30{ }^{\circ} \mathrm{C}$ for 5 days on cefsulodin-irgasannovobiocin agar (Becton Dickinson) (Schiemann, 1979). Strains Y. mollaretii CCUG $26331^{\mathrm{T}}$, Y. bercovieri CCUG $26329^{\mathrm{T}}$, Y. frederiksenii CCUG $11293^{\mathrm{T}}$, Y. aldovae CCUG $18770^{\mathrm{T}}, Y$. intermedia CCUG $11292^{\mathrm{T}}, \quad$ Y. kristensenii CCUG $11294^{\mathrm{T}}$, Y. rohdei CCUG $38833^{\mathrm{T}}$, Y. ruckeri CCUG $14190^{\mathrm{T}}$, Y. enterocolitica CCUG $11291^{\mathrm{T}}$, Y. enterocolitica CCUG $12369^{\mathrm{T}}, \quad$ Y. enterocolitica CCUG 7758 and $Y$. enterocolitica CCUG 8239A were obtained from the Culture Collection, University of Göteborg, Sweden, and investigated in parallel. Motility was checked by microscopic observation. Morphological properties were determined by 
Gram staining. The size and ultrastructure of the cells were determined by transmission electron microscopy. Colonies were harvested from trypticase soy medium (bioMérieux), pelleted by centrifugation and prefixed for $1 \mathrm{~h}$ at room temperature in $2.5 \%$ glutaraldehyde in $0.1 \mathrm{M}$ cacodylate buffer ( $\mathrm{pH} 7.2$ ) containing $0.1 \mathrm{M}$ sucrose. After washing overnight with the same buffer, the bacteria were fixed for $1 \mathrm{~h}$ at room temperature with $1 \%$ osmium tetroxide in $0.1 \mathrm{M}$ cacodylate buffer, dehydrated through increasing concentrations (25-100\%) of ethanol, and then embedded in Epon 812. Thin sections were cut and post-stained with a saturated solution of methanol uranyl acetate and lead citrate in water before examination on a Morgagni M 268D electron microscope (FEI France) at an operating voltage of $60 \mathrm{kV}$. Oxidase activity was detected by using a dimethyl-p-phenylenediamine oxalate disk (Sanofi Diagnostic Pasteur). Catalase activity was detected by emulsifying a colony in $3 \%$ hydrogen peroxide and checking for the presence of microscopic bubbles. Mannitol-fermenting colonies were identified by using an API 20E strip (bioMérieux), a commercial identification system for Enterobacteriaceae (Neubauer et al., 1998), according to the instructions of the manufacturer with the exception of incubation at $28{ }^{\circ} \mathrm{C}$ (Sharma et al., 1990). API 20E strips were read after 24,48 and $72 \mathrm{~h}$ incubation under a highly humidified atmosphere, and tentative identifications were obtained using the Analytical Profile Index, fourth edition (Archer et al., 1987; Sharma et al., 1990). API Coryne, Api NH and API 20A (bioMérieux) were used for further determination of pyrazinamidase, lipase, aesculin and salicin. Isolates were serotyped by slide agglutination with antisera against $Y$. enterocolitica O:3, O:8 and O:9 (Denka Seiken). Every test was done in triplicate on three separate days to ensure the reproducibility of the results.

After $24 \mathrm{~h}$ culture on MacConkey agar, DNA extraction, purification, degradation and $\mathrm{G}+\mathrm{C}$ content determination by HPLC were performed as described by Mesbah et al. (1989), except that a Waters 625 LC system with a Waters 486 Tenable Absorbance Detector and a Water 746 Data Module (Millipore) were used. Three determinations were done. DNA extracted from colonies by using Qiagen columns (QIAamp tissue kit) was used as a template for PCR amplification and sequencing of the 16S rRNA gene using primers fD1/rp2 (Weisburg et al., 1991). Four additional housekeeping genes, including $r p o B$, $h s p 60$, gyrB and $\operatorname{sod} A$, were amplified and sequenced. $r p o B$ gene amplification and sequencing was performed as described by Mollet et al. (1997). Because of limited sequence availability of the remaining three genes for some of the Yersinia species in GenBank, a 683 bp fragment of the $h s p 60$ gene was amplified and sequenced using primers hsp60-498F (5'-GGAAAAAGTCGGTAAAGAAGGCG-3') and hsp601181R (5'-GCTTTCTTCTCTTTCATTTCAACTTC-3') designed after alignment of the $h s p 60$ gene of $Y$. enterocolitica Y-108c (GenBank accession no. X68526), Y. pseudotuberculosis IP32953 (NC006155, locus_tag YPTB0405) and Y. pestis
CO92 (NC003143, locus_tag YPO0351). A 662 bp gyrB gene fragment was amplified and sequenced by using primers gyrB-303F (5'-CGGTAAATTTGACGATAACTCC$\left.3^{\prime}\right)$ and gyrB-965R (5'-ACAGCAATCAAGCCTTCACGGG$\left.3^{\prime}\right)$ designed after alignment of the gyrB gene of $Y$. enterocolitica ATCC 2610 (AB084022), Y. pseudotuberculosis IP32953 (NC006155, locus_tag YPTB3940) and Y. pestis CO92 (NC003143, locus_tag YPO4094). A 624 bp sodA gene fragment was amplified and sequenced by using the primer pair sodA-1F (5'-ATGAGTTAYTCACTGCCAT- $\left.3^{\prime}\right)$ and sodA-624R (5'-TTACTTRGCTTGAGCGAA-3') designed after alignment of the sodA gene of $Y$. enterocolitica WA314 (X96852), Y. pseudotuberculosis (NC006155, locus_tag YPTB3925) and Y. pestis CO92 (NC003143, locus_tag YPO4061). Products of sequencing reactions were recorded with an ABI Prism $3130 x l$ DNA sequencer following the standard protocol of the supplier (Perkin Elmer Applied Biosystems). The percentage similarity between the sequences was determined using the CLUSTAL $\mathrm{W}$ program supported by the PBIL website (http://npsa-pbilibcp.fr/). For phylogenetic analysis, sequences were trimmed in order to start and finish at the same nucleotide position for all the strains under study. Multisequence alignment was performed by using the CLUSTAL_X program, version 1.81 in the PHYLIP software package (Thompson et al., 1994). Phylogenetic trees were obtained from DNA sequences by using the neighbourjoining method with Kimura's two-parameter distance correction model with 1,000 bootstrap replications in the MEGA version 3.1 software package (Kumar et al., 2004). Phylogenetic trees based upon each gene sequence and one based on the combined gene sequences were then compared using the neighbour-joining and maximum-parsimony methods.

Isolates $50640^{\mathrm{T}}$ and 823 were shown to be Gram-negative bacilli and were motile at $28{ }^{\circ} \mathrm{C}$. The rods were $2.23 \mu \mathrm{m}$ long and $0.85 \mu \mathrm{m}$ wide, with one to two flagella of $6.75 \mu \mathrm{m}$ (Fig. 1). Biochemical characteristics that differentiate isolates $50640^{\mathrm{T}}$ and 823 from closely related Yersinia species are summarized in Table 1 . Both isolates were catalase-positive and oxidase-negative. An API 20E strip inoculated with isolate $50640^{\mathrm{T}}$ or 823 yielded a biochemical pattern indistinguishable from that of $Y$. enterocolitica coded as 1154723 in the API 20E system. Parallel inoculation of $Y$. enterocolitica CCUG $12369^{\mathrm{T}}$, Y. frederiksenii CCUG $11293^{\mathrm{T}}$ and Y. pseudotuberculosis IP 32953 yielded codes of 1154723, 1354733 and 1014113, respectively, allowing very good identification of these species. However, the codes 1114523 for Y. bercovieri and 1114523 for $Y$. mollaretii identified these strains as $Y$. enterocolitica according to the API 20E coding system. Isolates $50640^{\mathrm{T}}$ and 823 differed from Y. mollaretii CCUG $26331^{\mathrm{T}}$ and $Y$. bercovieri CCUG $26329^{\mathrm{T}}$ by exhibiting positive indole and inositol tests, and from Y. frederiksenii CCUG $11293^{\mathrm{T}}$ by the lack of L-rhamnose fermentation and citrate utilization. After $48-72 \mathrm{~h}$ incubation, isolates $50640^{\mathrm{T}}$ and 823 exhibited citrate utilization and weak acetoin production, resulting in a profile number of 1354723 that identified 


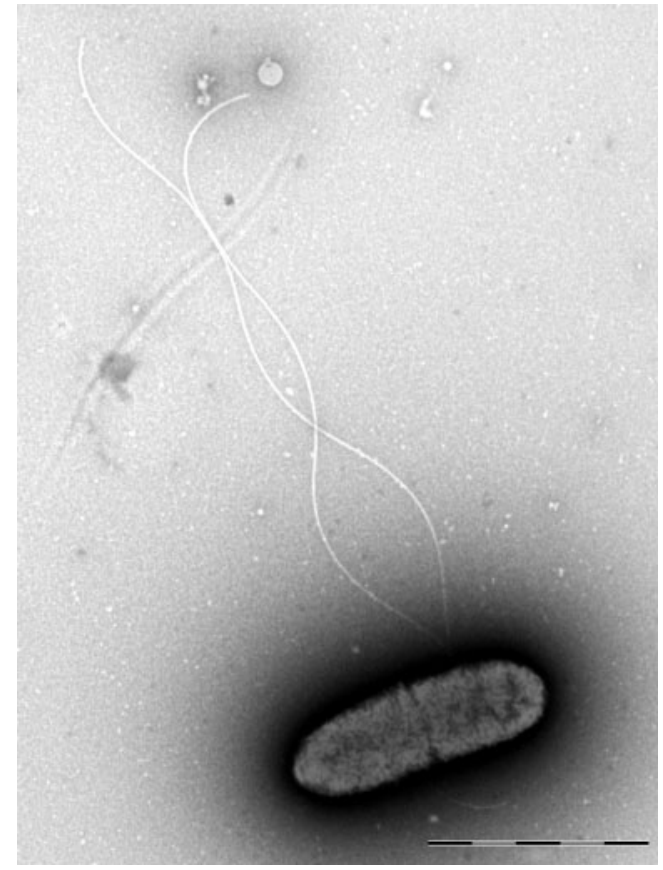

Fig. 1. Electron micrograph of cells of isolate $50640^{\top}$. Bar, $2 \mu \mathrm{m}$.

them as $Y$. enterocolitica (52\% confidence) or $Y$. frederiksenii ( $48 \%$ confidence). The two isolates were positive for salicin, aesculin and pyrazinamidase, but did not react with any of the tested Yersinia typing sera.

The DNA G+C content was $48.7 \pm 0.6 \mathrm{~mol} \%$. The 1461 bp $16 \mathrm{~S}$ rRNA gene sequences of isolates $50640^{\mathrm{T}}$ and 823 were identical and shared $98.7 \%$ similarity with $Y$. bercovieri, $98.5 \%$ with $Y$. mollaretii and $98.4 \%$ with $Y$. frederiksenii corresponding to 17, 20 and 21 bp differences, respectively (Table 2). The $16 \mathrm{~S}$ rRNA gene sequence did not discriminate $Y$. enterocolitica CCUG $11291^{\mathrm{T}}, Y$. enterocolitica CCUG $12369^{\mathrm{T}}$ and Y. enterocolitica CCUG 7758. As for the $h s p 60, \operatorname{gyr} B$, sodA and $r p o B$ gene sequences, isolates $50640^{\mathrm{T}}$ and 823 shared 93.5, 90.4, 92.4 and $96.6 \%$ similarity with the respective homologous sequences of Y. mollaretii, 93.0, 90.1, 89.1 and $96.3 \%$ with $Y$. bercovieri and 93.2, 89.8, 88.9 and $95.3 \%$ with $Y$. frederiksenii (Table 2). Comparison of sequences derived from isolates $50640^{\mathrm{T}}$ and 823 yielded one point mutation in $\mathrm{gyrB}$, two in $\operatorname{sod} A$, four in $h s p 60$ and five in $r p o B$.

Phylogenetic trees were constructed based upon each gene sequence, $16 \mathrm{~S}$ rRNA (1461 bp), hsp60 (635 bp), gyrB (619 bp), sodA (624 bp) and rpoB (1049 bp), and by combining the four housekeeping gene sequences (about $3000 \mathrm{nt}$ ) determined for 11 Yersinia species in addition to isolates $50640^{\mathrm{T}}$ and 823 (Figs 2 and 3). Bootstrap values $>75 \%$ in the $16 \mathrm{~S}$ rRNA gene tree occurred for only $7 / 12$ (58.3\%) nodes, too low to provide much confidence (Fig. 2). Likewise, $h s p 60-$, gyrB-, sodA- and rpoB-based phylogenetic trees showed low bootstrap values with only $7 / 13(51.8 \%)$, 5/12 (41.7\%), 4/13 (30.8\%) and 8/13 (61.5\%) nodes $>75 \%$, respectively (see supplementary Figs S1, S2, S3 and S4 available with the online version of this paper). In contrast, the combination of the four housekeeping gene sequences improved the bootstrap values with 12/13 $(92.3 \%)$ nodes $>75 \%(P<0.05)$ (Fig. 3$)$. This analysis also revealed that isolates $50640^{\mathrm{T}}$ and 823 formed a unique line within the genus Yersinia. A bootstrap value of $93 \%$ in the neighbour-joining tree supported the fork separating isolates $50640^{\mathrm{T}}$ and 823 from Y. mollaretii and Y. bercovieri, giving a high level of confidence to this analysis (Fig. 3). Parsimony and maximum-likelihood methods confirmed that isolates $50640^{\mathrm{T}}$ and 823 formed a lineage that was clearly different from closely related species and quite distant from other recognized Yersinia species. In most, but not all cases, the four housekeeping genes and the 16S rRNA gene sequence trees correlated well with each other, and agreed with a separate species status for isolates $50640^{\mathrm{T}}$ and 823 (Figs 2 and 3).

Two isolates, $50640^{\mathrm{T}}$ and 823 , of biochemically atypical Yersinia were recovered from haemodialysis unit water and well water. An API 20E strip misidentified these isolates as

Table 1. Biochemical characteristics that distinguish isolates $50640^{\top}$ and 823 from closely related species

Other tests including catalase, oxidase, $\beta$-galactosidase, arginine dihydrolase, lysine decarboxylase, ornithine decarboxylase, $\mathrm{H}_{2} \mathrm{~S}$, urease, tryptophan deaminase, gelatinase, glucose, mannitol, sorbitol, sucrose, melibiose, amygdalin, arabinose, salicin, pyrazinamidase and aesculin were not discriminant. +, Positive; -, negative; \pm , weakly positive after $48 \mathrm{~h}$.

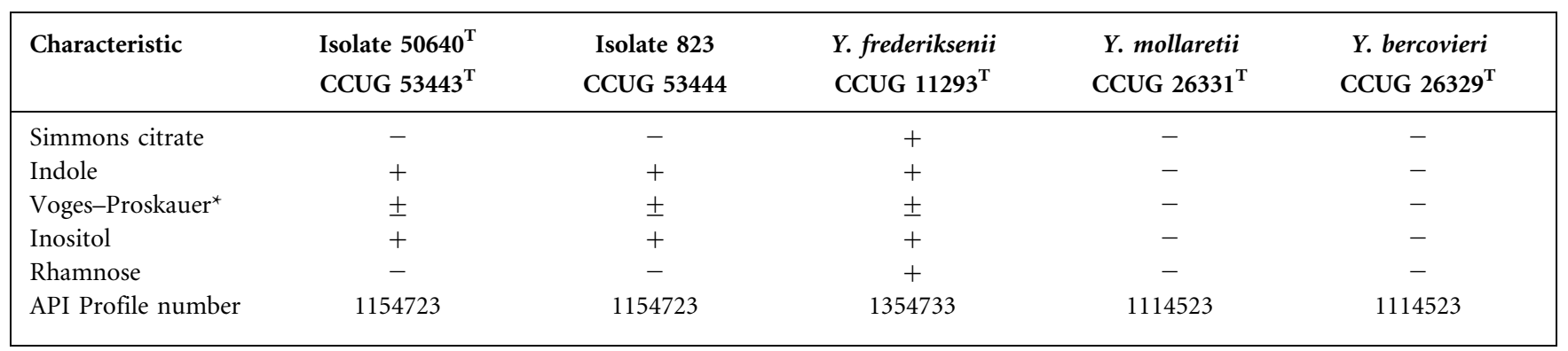

${ }^{\star}$ Determined after 3 days incubation at $28{ }^{\circ} \mathrm{C}$. 
Table 2. Gene sequence similarities of isolates $50640^{\top}$ and 823 with 11 Yersinia species, and similarity of $Y$. mollaretii and $Y$. bercovieri, and $Y$. aldovae and $Y$. intermedia with respect to 16S rRNA and four housekeeping genes

\begin{tabular}{|c|c|c|c|c|c|}
\hline Species & $\begin{array}{l}\text { 16S rRNA } \\
(1461 \mathrm{bp})\end{array}$ & $\begin{array}{c}\text { hsp60 } \\
(635 \mathrm{bp})\end{array}$ & $\begin{array}{c}g y r B \\
(619 \mathrm{bp})\end{array}$ & $\begin{array}{c}\operatorname{sod} A \\
(624 \mathrm{bp})\end{array}$ & $\begin{array}{c}\text { rpoB } \\
(1,049 \mathrm{bp})\end{array}$ \\
\hline Y. frederiksenii CCUG $11293^{\mathrm{T}}$ & 98.4 & 93.2 & 89.8 & 88.9 & 95.2 \\
\hline Y. bercovieri CCUG $26329^{\mathrm{T}}$ & 98.7 & 93.0 & 90.1 & 89.1 & 96.2 \\
\hline Y. mollaretii CCUG $26331^{\mathrm{T}}$ & 98.5 & 93.5 & 90.4 & 92.4 & 96.6 \\
\hline Y. aldovae CCUG $18770^{\mathrm{T}}$ & 98.2 & 92.1 & 88.2 & 88.6 & 94.3 \\
\hline Y. intermedia CCUG $11292^{\mathrm{T}}$ & 98.6 & 93.0 & 89.1 & 88.4 & 94.3 \\
\hline Y. kristensenii CCUG $11294^{\mathrm{T}}$ & 98.1 & 93.0 & 90.4 & 88.9 & 94.0 \\
\hline Y. rohdei CCUG $38833^{\mathrm{T}}$ & 98.2 & 90.8 & 90.4 & 84.4 & 95.6 \\
\hline Y. ruckeri CCUG $14190^{\mathrm{T}}$ & 98.4 & 88.6 & 89.6 & 22.7 & 94.3 \\
\hline Y. enterocolitica CCUG 7758 & 97.8 & 92.7 & 90.7 & 88.7 & 95.0 \\
\hline Y. enterocolitica CCUG 8239A & 98.3 & 93.0 & 90.4 & 89.2 & 95.1 \\
\hline Y. enterocolitica CCUG $11291^{\mathrm{T}}$ & 97.8 & 92.5 & 90.7 & 88.3 & 95.1 \\
\hline Y. enterocolitica CCUG $12369^{\mathrm{T}}$ & 97.8 & 92.5 & 90.7 & 88.3 & 95.0 \\
\hline Y. pestis $\mathrm{CO} 92$ & 98.5 & 91.6 & 89.3 & 88.7 & 93.5 \\
\hline Y. pseudotuberculosis IP32953 & 98.5 & 91.8 & 89.4 & 88.6 & 93.5 \\
\hline Y. mollaretii CCUG $26331^{\mathrm{T}}$ vs $Y$. bercovieri CCUG $26329^{\mathrm{T}}$ & 99.3 & 94.9 & 92.5 & 91.3 & 97.9 \\
\hline Y. aldovae CCUG $18770^{\mathrm{T}}$ vs $Y$. intermedia CCUG $11292^{\mathrm{T}}$ & 99.5 & 93.5 & 91.7 & 92.9 & 96.9 \\
\hline
\end{tabular}

Y. enterocolitica. However, the two isolates were positive for salicin, aesculin, pyrazinamidase, lipase, xylose, trehalose, indole and the Voges-Proskauer test, a pattern in agreement with the recent description of some $Y$. enterocolitica-like species (Hallanvuo et al., 2006). We observed a $1.3 \%$ divergence in the 16S rRNA gene sequence of isolates $50640^{\mathrm{T}}$ and 823 with that of $Y$. bercovieri, $1.5 \%$ with that of $Y$. mollaretii and $1.6 \%$ with that of $Y$. frederiksenii. These levels were below the $1.3 \%$ threshold proposed by Stackebrandt \& Ebers (2006) to delineate bacterial species by using $16 \mathrm{~S}$ rRNA gene sequencing, thus firmly suggesting that the isolates herein studied belong to a new species in agreement with their unique phenotypic profile.
We further characterized isolates $50640^{\mathrm{T}}$ and 823 by sequencing four housekeeping genes to fulfil the recommendations of the ad-hoc committee for the re-evaluation of the definition of the bacterial species (Stackebrandt et al., 2002) and as recently suggested for Yersinia isolates speciation (Kotetishvili et al., 2005). These four housekeeping genes are spaced well apart on the genome and could potentially reflect the evolution of the whole genome (Thomson et al., 2006). The topologies of the four housekeeping-based phylogenetic trees and the 16S rRNA gene-based phylogenetic tree were quite similar. However, the four housekeeping genes were more consistent with the biochemical species designation than the 16S rRNA gene

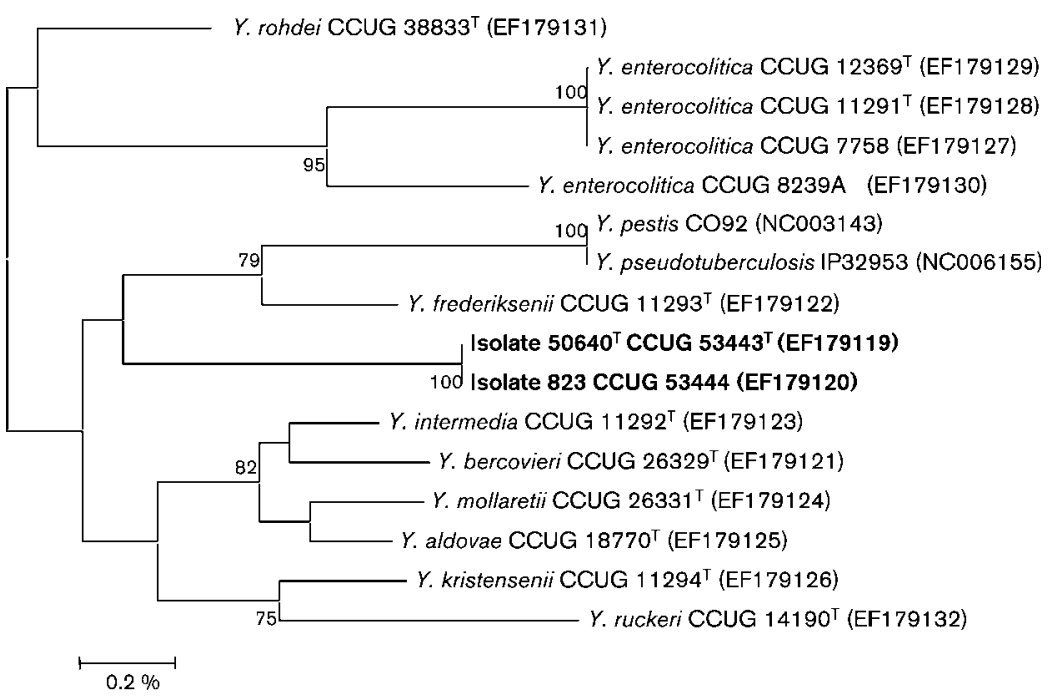

Fig. 2. Phylogenetic tree based on the $16 \mathrm{~S}$ rRNA gene sequences of isolates $50640^{\top}$ and 823 and 11 Yersinia species prepared by using the neighbour-joining method and Kimura's two-parameter distance correction model. GenBank accession numbers are given in parentheses. The support of each branch, as determined from 100 bootstrap samples, is indicated by the value (\%) at each node. Only bootstrap values $\geqslant 75 \%$ are indicated. The scale bar represents a $0.2 \%$ difference in nucleotide sequence. 


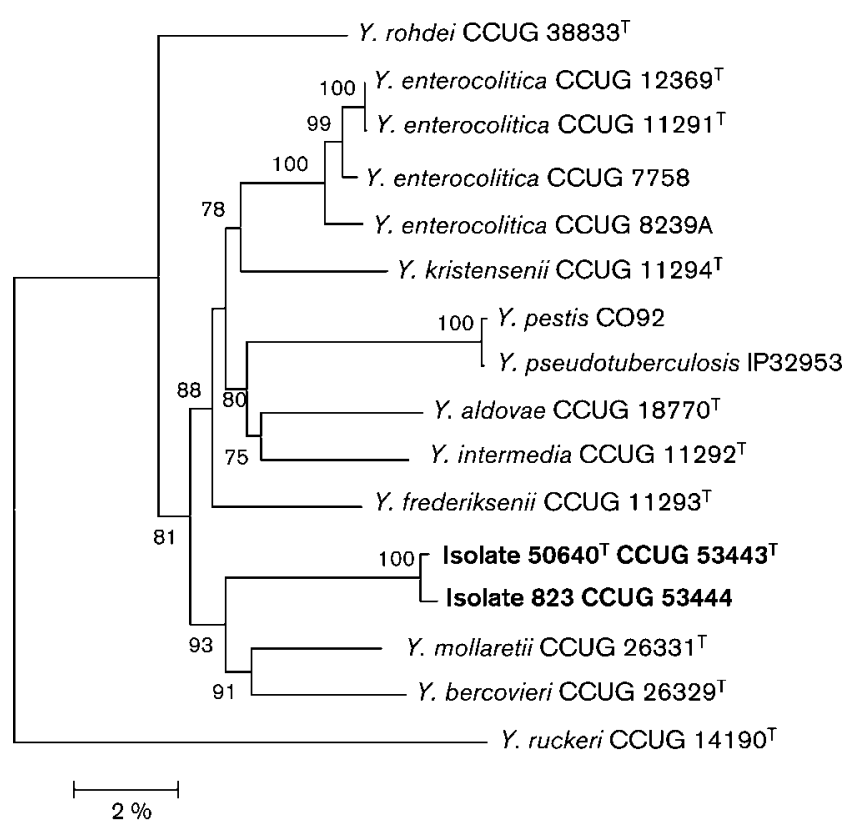

Fig. 3. Phylogenetic tree based on concatened $r p o B, h s p 60$, gyr $B$ and $\operatorname{sod} A$ gene sequences of isolates $50640^{\top}$ and 823 and 11 Yersinia species prepared by using the neighbour-joining method and Kimura's two-parameter distance correction model. The support of each branch, as determined from 100 bootstrap samples, is indicated by the value (\%) at each node. Only bootstrap values $\geqslant 75 \%$ are indicated. The scale bar represents a $2 \%$ difference in nucleotide sequence.

analysis, i.e. $Y$. mollaretii and $Y$. bercovieri, which exhibited a similar biochemical profile, were in the same branch in the four housekeeping gene trees (Fig. 3) whereas they were in separate branches in the 16S rRNA gene tree (Fig. 2). The four housekeeping genes yielded bootstrap values higher than those derived from the 16S rRNA gene. These data indicate that the 16S rRNA gene sequence alone cannot resolve the phylogenetic relationships between all currently recognized Yersinia species.

By combining the four housekeeping genes studied herein, we found that $Y$. mollaretii and $Y$. bercovieri on one hand, and $Y$. aldovae and $Y$. intermedia on the other were closely related. In the $r p o B, g y r B, h s p 60$ and sodA gene sequences, similarity levels between $Y$. mollaretii and $Y$. bercovieri were 97.9, 92.5, 94.9 and $91.3 \%$, and 96.9, 91.7, 93.5 and $92.9 \%$ between $Y$. aldovae and $Y$. intermedia, respectively (Table 2). Isolates $50640^{\mathrm{T}}$ and 823 showed less similarity with respect to the four housekeeping genes with all other Yersinia species (Table 2). Although there are no validated cut-off values for Yersinia species delineation, we observed that similarity values of $<98.0 \%$ for $r p o B,<92.5 \%$ for gyrB, $<95.0 \%$ for $h s p 60$ and $<93.0 \%$ for sodA effectively delineated the currently recognized species in the Yersinia genus. These values supported previous DNA-DNA hybridization data for the genus (Bottone, 1997). As for the $r p o B$ gene, these cut-off values agree with the similarity value ( $97.6 \%$ over $1049 \mathrm{bp}$ ) that delineates two other enteric species, Klebsiella variicola and Klebsiella pneumoniae; these species share $99.3 \% 16 \mathrm{~S}$ rRNA gene sequence similarity (Rosenblueth et al., 2004). The same strategy, based on this short $r p o B$ gene portion, has been used to delineate Klebsiella singaporensis from $K$. pneumoniae, two species which share $99.3 \% 16 \mathrm{~S}$ rRNA gene sequence similarity and $97.5 \% \mathrm{rpoB}$ gene sequence similarity (Li et al., 2004). Based on a 512 bp portion of the $r p o B$ gene sequence reported for Enterobacteriaceae species (Mollet et al., 1997), these authors found $97.7-98.8 \%$ similarity among representative species of three genetic groups, i.e. Klebsiella, Escherichia and Salmonella. We found that the interspecies similarity in this region for the 11 Yersinia species examined in this study varied from $93.5 \%$ (Y. pestis and Y. enterocolitica) to $98.8 \%$ (Y. kristensenii and Y. enterocolitica). Also, our data showed that isolates $50640^{\mathrm{T}}$ and 823 shared $96.6 \%$ similarity with $Y$. mollaretii, $96.2 \%$ with $Y$. bercovieri, and $95.2 \%$ with $Y$. frederiksenii. This analysis further supported that isolates $50640^{\mathrm{T}}$ and 823 formed a novel species within the genus Yersinia.

Comparative 16S rRNA gene sequence analysis revealed that isolates $50640^{\mathrm{T}}$ and 823 shared $100 \%$ sequence similarity with non-typable Yersinia isolate 11A recovered from raw milk samples in Queensland, Australia (Ibrahim et al., 1997). The dendrogram of relationships based on the $16 \mathrm{~S}$ rRNA gene sequence indicated that the atypical isolate $11 \mathrm{~A}$ formed an individual line of descent distinct from $Y$. frederiksenii (Ibrahim et al., 1997). Although 16S rRNA gene sequence identity does not necessarily indicate close relatedness, this Yersinia isolate also exhibited a similar biochemical phenotype to isolates $50640^{\mathrm{T}}$ and 823 . It yielded only $41 \%$ DNA-DNA relatedness to the $Y$. frederiksenii type strain (Ibrahim et al., 1997) and has been tentatively assigned to $Y$. frederiksenii hybridization group 2 (unnamed genospecies 2). Isolate 11A, however, was not available for this study and the question of its taxonomic status remains open, pending further molecular comparisons with isolates $50640^{\mathrm{T}}$ and 823 .

Original phenotypic traits and molecular analysis, including sequence analyses of the $16 \mathrm{~S}$ rRNA, $h s p 60$, sodA, gyrB and $r$ poB genes, identified isolates $50640^{\mathrm{T}}$ and 823 as belonging to a novel Yersinia species, for which the name Yersinia massiliensis is proposed.

\section{Description of Yersinia massiliensis sp. nov.}

Yersinia massiliensis (mas.si.li.en'sis. L. fem. adj. massiliensis pertaining to Massilia, the ancient Roman name of Marseille, France, where the type strain was isolated).

Freshwater-living Gram-negative, coccoid rod, motile with one to two flagella of $6.75 \mu \mathrm{m}$. Colonies appeared on $5 \%$ blood sheep agar after $24 \mathrm{~h}$ incubation. The colonies are circular and convex. Growth occurs at 28 and $37^{\circ} \mathrm{C}$. Cells are catalase-positive and oxidase-negative. Positive reaction for urease, indole, ornithine decarboxylase, arginine dihydrolase, lysine decarboxylase and tryptophan deaminase, 
and delayed citrate utilization. Glucose, mannitol, inositol, sorbitol, sucrose, amygdale and arabinose are fermented, but rhamnose and melobiose are not. Gelatin was not hydrolysed. Voges-Proskauer test was negative after $24 \mathrm{~h}$ incubation and weakly positive on day 3 . The $\mathrm{G}+\mathrm{C}$ content was $49.3 \mathrm{~mol} \%$. 16S rRNA, hsp60, gyrB, sodA and $r p o B$ gene sequences share $98.5,93.5,90.4,92.4$ and $96.6 \%$ similarity with Y. mollaretii, 98.7, 93.0, 90.1, 89.1 and $96.2 \%$ similarity with $Y$. bercovieri and 98.4, 93.2, 89.8, 88.9 and $95.2 \%$ similarity with $Y$. frederiksenii, respectively.

The type strain, isolated in a dialysis unit from the hospital water distribution system in Marseilles, France, is $50640^{\mathrm{T}}$ $\left(=\right.$ CIP $\quad 109351^{\mathrm{T}}=$ CCUG $\left.53443^{\mathrm{T}}\right)$. Strain $823 \quad(=\mathrm{CIP}$ $109352=$ CCUG 53444) was isolated from well water in southern France.

\section{Acknowledgements}

We are grateful to Bernard Campagna for his technical assistance in electron microscopy and to Dr Saravanan Ayyadurai for expert reviewing of the manuscript.

\section{References}

Archer, J. R., Schell, R. F., Pennell, D. R. \& Wick, P. D. (1987). Identification of Yersinia spp. with the API 20E system. J Clin Microbiol 25, 2398-2399.

Bercovier, H. \& Mollaret, H. H. (1984). Genus XIV. Yersinia Van Loghem 1944, 15 ${ }^{\mathrm{AL}}$. In Bergey's Manual of Systematic Bacteriology, vol. 1, pp. 498-506. Edited by N. R. Krieg \& J. G. Holt. Baltimore: Williams \& Wilkins.

Bottone, E. J. (1997). Yersinia enterocolitica: the charisma continues. Clin Microbiol Rev 10, 257-276.

Bottone, E. J. (1999). Yersinia enterocolitica: overview and epidemiologic correlates. Microbes Infect 1, 323-333.

Carniel, E. \& Mollaret, H. H. (1990). Yersiniosis. Comp Immunol Microbiol Infect Dis 13, 51-58.

Gray, L. D. (1995). Escherichia, Salmonella, Shigella, and Yersinia. In Manual of Clinical Microbiology, 6th edn, pp. 450-456. Edited by P. R. Murray, E. J. Baron, M. A. Pfaller, F. C. Tenover \& R. H. Yolken. Washington DC: ASM Press.

Hallanvuo, S., Peltola, J., Heiskanen, T. \& Siitonen, A. (2006). Simplified phenotypic scheme evaluated by 16S rRNA sequencing for differentiation between Yersinia enterocolitica and Y. enterocolitica-like species. J Clin Microbiol 44, 1077-1080.

Ibrahim, A., Liesack, W., Steigerwalt, A. G., Brenner, D. J., Stackebrandt, E. \& Robins-Browne, R. M. (1997). A cluster of atypical Yersinia strains with a distinctive $16 \mathrm{~S}$ rRNA signature. FEMS Microbiol Lett 146, 73-78.

Kotetishvili, M., Kreger, A., Wauters, G., Morris, J. G., Jr, Sulakvelidze, A. \& Stine, O. C. (2005). Multilocus sequence typing for studying genetic relationships among Yersinia species. J Clin Microbiol 43, 2674-2684.
Kumar, S., Tamura, K. \& Nei, M. (2004). MEGA3: integrated software for Molecular Evolutionary Genetics Analysis and sequence alignment. Brief Bioinform 5, 150-163.

Li, X., Zhang, D., Chen, F., Ma, J., Dong, Y. \& Zhang, L. (2004). Klebsiella singaporensis sp. nov., a novel isomaltulose-producing bacterium. Int J Syst Evol Microbiol 54, 2131-2136.

Mesbah, M., Premachandran, U. \& Whitman, W. B. (1989). Precise measurement of the $\mathrm{G}+\mathrm{C}$ content of deoxyribonucleic acid by highperformance liquid chromatography. Int J Syst Bacteriol 39, 159-167.

Mollet, C., Drancourt, M. \& Raoult, D. (1997). rpoB sequence analysis as a novel basis for bacterial identification. Mol Microbiol 26, 1005-1011.

Neubauer, H., Sauer, T., Becker, H., Aleksic, S. \& Meyer, H. (1998). Comparison of systems for identification and differentiation of species within the genus Yersinia. J Clin Microbiol 36, 3366-3368.

Perry, R. D. \& Fetherston, J. D. (1997). Yersinia pestis - etiologic agent of plague. Clin Microbiol Rev 10, 35-66.

Robins-Browne, R. M., Ciancosi, S., Bordun, A.-M. \& Wauters, G. (1991). Pathogenicity of Yersinia kristensenii for mice. Infect Immun 59, 162-167.

Rosenblueth, M., Martinez, L., Silva, J. \& Martinez-Romero, E. (2004). Klebsiella variicola, a novel species with clinical and plantassociated isolates. Syst Appl Microbiol 27, 27-35.

Schiemann, D. A. (1979). Synthesis of a selective agar medium for Yersinia enterocolitica. Can J Microbiol 25, 1298-1304.

Sharma, N. K., Doyle, P. W., Gerbasi, S. A. \& Jessop, J. H. (1990). Identification of Yersinia species by the API 20E. J Clin Microbiol 28, 1443-1444.

Sprague, L. D. \& Neubauer, H. (2005). Yersinia aleksiciae sp. nov. Int J Syst Evol Microbiol 55, 831-835.

Stackebrandt, E. \& Ebers, J. (2006). Taxonomic parameters revisited: tarnished gold standards. Microbiol Today 33, 152-155.

Stackebrandt, E., Frederiksen, W., Garrity, G. M. \& other authors (2002). Report of the ad hoc committee for the re-evaluation of the species definition in bacteriology. Int J Syst Evol Microbiol 52, 1043-1047.

Sulakvelidze, A. (2000). Yersiniae other than Y. enterocolitica, $Y$. pseudotuberculosis, and Y. pestis, the ignored species. Microbes Infect 2, 497-513.

Sulakvelidze, A., Kreger, A., Joseph, A., Robins-Browne, R. M., Fasano, A., Wauters, G., Harnett, N., DeTolla, L. \& Morris, J. G., Jr (1999). Production of enterotoxin by Yersinia bercovieri, a recently identified Yersinia enterocolitica-like species. Infect Immun 67, 968-971.

Thompson, J. D., Higgins, D. G. \& Gibson, T. J. (1994). CLUSTAL W, improving the sensitivity of progressive multiple sequence alignment through sequence weighting, position-specific gap penalties and weight matrix choice. Nucleic Acids Res 22, 4673-4680.

Thomson, N. R., Howard, S., Wren, B. W., Holden, M. T. G., Crossman, L., Challis, G. L., Churcher, C., Mungall, K., Brooks, K. \& other authors (2006). The complete genome sequence and comparative genome analysis of the high pathogenicity Yersinia enterocolitica strain 8081. PLoS Genet 2, e206.

Weisburg, W. G., Barns, S. M., Pelletier, D. A. \& Lane, D. J. (1991). $16 \mathrm{~S}$ ribosomal DNA amplification for phylogenetic study. J Bacteriol 173, $697-703$. 